\title{
ave open Determinants of vulnerability in early childhood development in Ireland: a cross-sectional study
}

\author{
Margaret Curtin, ${ }^{1}$ Jamie Madden, ${ }^{1}$ Anthony Staines, ${ }^{2}$ Ivan J Perry ${ }^{1}$
}

To cite: Curtin M, Madden J, Staines $A$, et al. Determinants of vulnerability in early childhood development in Ireland: a cross-sectional study. BMJ Open 2013;3: e002387. doi:10.1136/ bmjopen-2012-002387

- Prepublication history and additional material for this paper are available online. To view these files please visit the journal online (http://dx.doi.org/10.1136/ bmjopen-2012-002387).

- Additional material is published online only. To view please visit the journal online (http://dx.doi.org/10. 1136/bmjopen-2012002387).

Received 26 November 2012 Revised 30 March 2013 Accepted 3 April 2013

This final article is available for use under the terms of the Creative Commons Attribution Non-Commercial 2.0 Licence; see http://bmjopen.bmj.com

${ }^{1}$ Department of Epidemiology and Public Health, University College Cork, Cork, Ireland ${ }^{2}$ School of Nursing and Human Sciences, Dublin City University, Dublin, Ireland

Correspondence to Margaret Curtin; m.curtin@ucc.ie

\section{ABSTRACT}

Objectives: Early childhood development strongly influences lifelong health. The Early Development Instrument (EDI) is a well-validated population-level measure of five developmental domains (physical health and well-being, social competence, emotional maturity, language and cognitive skills, and communication skills and general knowledge) at school entry age. The aim of this study was to explore the potential of EDI as an indicator of early development in Ireland.

Design: A cross-sectional design was used.

Setting: The study was conducted in 42 of 47 primary schools in a major Irish urban centre.

Participants: EDI (teacher completed) scores were calculated for 1243 children in their first year of fulltime education. Contextual data from a subset of 865 children were collected using a parental questionnaire. Primary and secondary outcome measures: Children scoring in the lowest $10 \%$ of the population in one or more domains were deemed 'developmentally vulnerable'. Scores were correlated with contextual data from the parental questionnaire.

Results: In the sample population, $29 \%$ of children were not developmentally ready to engage in school. Factors associated with increased risk of vulnerability were being male OR 2.1 ( $\mathrm{Cl} 1.6$ to 2.7); under 5 years OR 1.5 (Cl 1.1 to 2.1) and having English as a second language OR 3.7 ( $\mathrm{Cl} 2.6$ to 5.2). Adjusted for these demographics, low birth weight, poor parent/child interaction and mother's lower level of education showed the most significant ORs for developmental vulnerability. Calculating population attributable fractions, the greatest population-level risk factors were being male $(35 \%)$, mother's education $(27 \%)$ and having English as a second language (12\%).

Conclusions: The EDI and linked parental questionnaires are promising indicators of the extent, distribution and determinants of developmental vulnerability among children in their first year of primary school in Ireland.

\section{BACKGROUND}

There is significant epidemiological evidence that early childhood development (from gestation to age 6) strongly influences lifelong

\section{ARTICLE SUMMARY}

\section{Article focus}

- This study demonstrates that a significant population level variation exists in healthy child development in Ireland.

- The Early Development Instrument (EDI) is a unique, well-validated population level instrument that allows us to track all five domains of early development and identify populations of children at risk.

- When used in conjunction with a parental questionnaire, factors that impact on child development at the child and family levels can be identified.

\section{Key messages}

- A direct population level evidence based on normal child development is needed both as an indicator of child health and a predictor of future outcomes.

- Three child-level demographic factors (age, gender and language) accounted for over half of the population level risk of developmental vulnerability, reinforcing the need for universal early childhood programmes which are cognisant of these variations.

Strengths and limitations of this study

- This is the first peer-reviewed population level study published in Europe assessing child development outcomes across multiple domains using EDI.

- The study identifies proximal factors associated with child development; yet children and families do not live in a vacuum. Further research is needed to identify associated factors in the broader sociocultural environment.

health trajectories. ${ }^{1}$ Indeed, major public health problems such as obesity, heartdisease and mental health problems can be seen to have roots in early childhood. ${ }^{2}{ }^{3}$ This results from a complex interplay between genetic make-up, in utero development, and both prenatal and postnatal environmental factors, all of which influence brain development in the first 5 years of life. ${ }^{4}$ 
There is also evidence of a social gradient in child development, ${ }^{5}$ with children from poorer backgrounds doing less well in school and entering into an intergenerational cycle of reduced employment opportunities, higher fertility and health inequalities. ${ }^{6}$ The long-term social and economic gains of investing in the early years are also recognised. ${ }^{7}$ Kershaw $e t a l^{8}$ estimate that the cost of preventable early childhood vulnerability to the Canadian economy is between $\$ 2.2$ and $\$ 3.4$ trillion.

The challenge for public health is to give due consideration to early childhood development both as an indicator of child health and as a predictor of future outcomes. Child development has been recognised as a key social determinant. ${ }^{910}$ Moreover, the relatively large numbers of children with less pronounced development delay are a potentially greater burden than a small number of children at high risk, ${ }^{11}$ leading to a need for a population health approach. ${ }^{12}$ Yet, measurement of child development is usually in the form of a diagnostic which aims to identify children at greatest risk and provide appropriate individual care, leaving a dearth of research evidence on which to build population level strategies. ${ }^{13}{ }^{14}$ In this context, a direct population level evidence based on normal child development is needed.

The Early Development Instrument (EDI) is an internationally accepted, validated tool which has the potential to provide such an evidence base. ${ }^{15}$ In Australia, EDI (AEDI) has been used universally as a census of child development and has revealed significant variation across states and territories. ${ }^{16}$ While EDI has been implemented at a population level in Scotland, Sweden and Kosovo, this is the first peer reviewed population-level study published in Europe assessing child development outcomes across multiple domains, and using EDI and a linked parental questionnaire. The overall objective of the study was to ascertain the proportion of children who were developmentally ready for school in a representative sample of schools in a major urban centre in Ireland using EDI and to examine associated factors. The study also aimed to assess the feasibility of implementing EDI and its performance in this setting.

Ireland is a largely homogeneous country with $85.8 \%$ of the population ethnically White Irish and a further $9.3 \%$ of other white ethnic background, primarily British. ${ }^{17}$ Cork is one of five major urban centres. While all these centres are comprised of areas of concentrated affluence and disadvantage, there are similar overall rates of key socioeconomic indicators including unemployment, lone-parent families and education. ${ }^{18}$ There is a total population of 64937 5-year-olds. A minority $(1.1 \%)$ of Irish children are members of the Traveller Community. Moreover, $19.5 \%$ are considered at risk of poverty and $8 \%$ live in consistent poverty. ${ }^{19}$ The education system is static throughout the country.

\section{METHODS}

This observational study of child development was implemented with children in their first year of formal education (in Ireland, this is referred to as 'Junior Infants') in 42 of the 47 primary schools in Cork city. Five schools in the city declined to take part. These declining schools were representative of a cross section of schools in Cork-one boys school, one girls school, one large mixed, middle-income school, one designated a disadvantaged school and one Irish-speaking schooland their omission would not have affected the representativeness of the demographic composition of the study. A further four schools agreed to participate in the study but chose not to administer the parental questionnaire as they believed it would put undue pressure on parents with literacy challenges. These were all designated disadvantaged schools and this has contributed to the under-representation of the most vulnerable children in the parental study.

All eligible children in the participating schools were invited to be included in the study. Eligibility criteria were: being in the latter half of the first year of formal education (ie, having completed a minimum of 4-5 months of education), being known by the teacher for more than 1 month and not having left the school.

\section{Measurement of child development-the early development instrument}

Child development at school-entry age was measured using EDI. This population level measure was designed at the Offord Centre for Child Studies, McMaster University, Hamilton, Ontario in the late 1990s to measure the extent to which children have attained the physical, social, emotional and cognitive maturity necessary to engage in school activities. ${ }^{20}$ EDI is a community or population level measure, not an individual screening or diagnostic tool. The underlying focus is that of a population health approach, that is, small modifications of risk for large numbers are more effective at producing change than large modifications for small numbers. ${ }^{12}$ It can be retrospective, focusing on early childhood development outcomes; or predictive, informing school and child-health programmes. ${ }^{20}$ The instrument consists of 5 domains, 16 subdomains and 104 questions. The domains and subdomains are outlined in table 1.

EDI is a well-validated instrument which has undergone extensive psychometric testing both in Canada and Australia. ${ }^{15} 20-23$ It has also been proven valid for use in minority populations. ${ }^{24}$ In this Irish study, EDI had good internal consistency by domains with Cronbach $\alpha$ of between 0.8 and 0.96 .

\section{Parental questionnaire}

In 2003, a parental questionnaire was developed and tested by the Offord Centre to complement the results of EDI and to provide a deeper population level context to the lives of children. ${ }^{20}$ This questionnaire was adapted to suit the Irish context incorporating validated questions from the Growing Up in Ireland Study ${ }^{25}$ and the SLAN Survey of Lifestyles, Behaviour and Nutrition 
Table 1 Child development outcomes measured by EDI

\begin{tabular}{|c|c|}
\hline EDI domains/subdomains & Expected behaviour \\
\hline \multicolumn{2}{|l|}{ Physical health and well-being } \\
\hline Physical readiness for school day & Usually dressed appropriately for school and not tired, late or hungry \\
\hline Physical independence & $\begin{array}{l}\text { Can look after own personal needs appropriately; established hand } \\
\text { preference, well coordinated, and does not suck a thumb/finger }\end{array}$ \\
\hline Gross and fine motor skills & $\begin{array}{l}\text { Physically able to participate in school and excellent or good gross and fine } \\
\text { motor skills }\end{array}$ \\
\hline \multicolumn{2}{|l|}{ Social competence } \\
\hline Overall social competence & $\begin{array}{l}\text { Very good ability to play and get along with various children; usually } \\
\text { cooperative and self-confident }\end{array}$ \\
\hline Responsibility and respect & $\begin{array}{l}\text { Respect for others and for property; follows rules and takes care of materials; } \\
\text { accepts responsibility for actions, and shows self-control }\end{array}$ \\
\hline Approaches to learning & $\begin{array}{l}\text { Can work neatly, independently, and solve problems; follows instructions and } \\
\text { class routines; easily adjusts to changes }\end{array}$ \\
\hline Readiness to explore new things & $\begin{array}{l}\text { Curious about the surrounding world, and eager to explore new books, toys } \\
\text { and games }\end{array}$ \\
\hline \multicolumn{2}{|l|}{ Emotional maturity } \\
\hline Pro-social and helping behaviour & $\begin{array}{l}\text { Helping someone hurt, sick or upset; offering to help spontaneously; inviting } \\
\text { bystanders to join in }\end{array}$ \\
\hline Anxious and fearful behaviour & $\begin{array}{l}\text { Seldom or never showing anxious behaviours; happy and able to enjoy } \\
\text { school; comfortable being left at school by caregivers }\end{array}$ \\
\hline Aggressive behaviour & $\begin{array}{l}\text { Seldom or never showing aggressive behaviours; not using aggression to } \\
\text { solve conflict, not having temper tantrums, and not mean to others }\end{array}$ \\
\hline Hyperactivity and inattention & $\begin{array}{l}\text { Not showing hyperactive behaviours; able to concentrate, attend to chosen } \\
\text { activities, wait their turn, and usually think before doing }\end{array}$ \\
\hline \multicolumn{2}{|l|}{ Language and cognitive } \\
\hline Basic literacy skills & $\begin{array}{l}\text { Has basic literacy skills: can handle a book, identify some letters and attach } \\
\text { sounds to some letters, show awareness of rhyming words, know the writing } \\
\text { directions, and write their own name }\end{array}$ \\
\hline Interest literacy/numeracy and memory & $\begin{array}{l}\text { Showing interest in books and reading, math and numbers, and no difficulty } \\
\text { remembering things }\end{array}$ \\
\hline Advanced literacy skills & $\begin{array}{l}\text { Can read simple, complex words or sentences, write voluntarily, write simple } \\
\text { words or sentences }\end{array}$ \\
\hline Basic numeracy skills & $\begin{array}{l}\text { Can count to } 20 \text {, recognise shapes and numbers, compare numbers, sort and } \\
\text { classify, use one-to-one correspondence, and understand simple time } \\
\text { concepts }\end{array}$ \\
\hline \multicolumn{2}{|l|}{ Communication and general knowledge } \\
\hline Communication and general knowledge & $\begin{array}{l}\text { Can communicate easily and effectively, can participate in storytelling or } \\
\text { imaginative play, articulate clearly, show adequate general knowledge, and is } \\
\text { proficient in their native language }\end{array}$ \\
\hline
\end{tabular}

in Ireland. $^{26}$ It consists of seven sections: child health and development; child care; pre-school; school; family; neighbourhood and background information.

\section{Data collection}

EDI is a teacher-completed questionnaire based on a 5 month observation of the children from the date when they start school, and it was therefore implemented in the latter half of the first year of formal education. Prior to completing the questionnaires, the teachers were given a short training and with each being issued with an EDI guide book. Children were not present when the questionnaire was completed and no individual identifiers were recorded. Each child was assigned a form ID which was used on both the EDI and Parental Questionnaire.
Passive consent was used in line with previous EDI studies in Canada. An information letter was distributed to all parents by the class teacher 2 weeks before commencing the study. Parents were given detailed information on the study and asked to contact the school if they did not want their child included. A total of seven parents opted not to participate. Ethical approval was granted by the Clinical Research Ethics Committee of the Cork Teaching Hospitals.

The parental questionnaires were distributed in school bags or homework folders. Each parental pack contained a letter of explanation, a questionnaire (again with no individual identifier) and a blank envelope in which to return the questionnaire sealed to the school. Parents were reassured that the envelope would not be opened at the school. 


\section{Developmental scoring}

EDI scores were calculated for each developmental domain, that is, Physical Health and Well-being; Social Competence; Emotional Maturity; Language and Cognitive Development; and Communication Skills and General Knowledge. All questions had a two-point or three-point Likert-type response format (yes, no, don't know; very true, sometimes or somewhat true, never or not true, don't know). All responses had a score of 0-10 (two-point answers were scored 0 and 10; three-point answers were scored 0,5 and10). 'Don't know' responses were not scored. Domain scores refer to the child's mean score in that domain-ranging between 0 and 10 . Higher scores indicate better results.

Children who scored in the lowest $10 \%$ of the study population in one or more of the five domains of the EDI were classed as 'vulnerable'. The $10 \%$ cut-off is recommended because it is higher than the typical clinical cut-offs and should therefore include children who may be more difficult to diagnose. ${ }^{27}$ Those scoring in the lowest $10-25 \%$ for one or more domains were deemed 'at risk' and children who scored in the top $75 \%$ were 'on track' in that domain. Each domain was scored separately as children who are vulnerable in one area cannot compensate through competence in another. All scores were aggregated to the group level. In the absence of an Irish normative sample, to ensure the validity of the cut-off points, data were also scored against Canadian normative data. There was a $99 \%$ correlation between 'vulnerability' using the Irish and Canadian cut-off points. In four of the five domains, there was $100 \%$ correlation between vulnerability using the Irish and Canadian cut-off points.

Data from the parental questionnaires were linked to the teacher filled questionnaire using the Form ID number and the matching was cross-checked using the recorded date of birth and gender. Again, questions were constructed in a Likert-type response format-yes, no or three to five response options. Demographic questions on the child's date of birth and birth weight were also included.

\section{Explanatory variables}

The child's age was calculated from their date of birth and the date on which the form was completed and reported in years and months. 'Children for whom English is a second language (ESL)' refers to those reported by the teacher to have a first language other than English. Members of the Traveller Community were children who were known by school to be part of this Irish ethnic minority group.

'Children identified as special needs' refers to those children who had already been identified as needing special assistance in the classroom. In Ireland, this is defined as having a 'Special Education Condition' which has been recognised through a standardised assessment process. $^{28}$
Parental reported birth weight was used to calculate whether the child had a low birth weight, that is, less than $2.5 \mathrm{~kg}$. Parental report of birth weight has been proven to be adequately accurate to be acceptable for research purposes. ${ }^{29}$

Parents were asked how much time (to the nearest hour) the child spent watching television, using the computer or playing video games on a typical school day. This was coded into ' 1 or less', '2-3' and ' 4 or more' hours.

\section{Data analysis}

SPSS PASW Statistic 18 was used to analyse data. Each child's EDI scores were calculated by the Offord Centre for Child Studies in line with the international EDI process. Initial analysis involved a cross-tabulation of potential risk items from the teacher completed EDI questionnaire (ie, gender, age, ESL, pre-school attendance and membership of the Traveller Community) against the child's score in each of the developmental domains.

All further analyses reported here were confined to the subgroup of children for whom parental data were available. Univariate analysis was used to explore factors associated with 'vulnerability', that is, being in the lowest $10 \%$ of the target population in one or more domains. Factors which proved significant $(p<0.05)$ were then entered into logistic regression models to predict the likelihood of vulnerability on EDI scores. The first model adjusted for age, gender and ESL. The second model adjusted for all other factors.

Population attributable fractions (PAFs) were used to calculate the proportion of risk attributed to each of the factors in the final regression. ${ }^{30} 31$ This was calculated using the 'punaf' command in STATA V.12, which calculates CIs for PAF, and also for scenario means and their ratio, known as PAF. Punaf uses the method for estimating PAFs recommended by Greenland and Drescher ${ }^{32}$ for cohort and cross-sectional studies.

\section{RESULTS}

EDI questionnaires were distributed to teachers of 1366 children. A total of $1243(92 \%)$ children were returned completed and valid. Of these, $45 \%(n=563)$ were girls. The average age at which children in the study started school was 4 years and 9 months. The youngest was 3 years 11 months and the oldest 6 years and 1 month.

There was considerable diversity in first language with $12.7 \%$ of the children reported to have English as a Second Language (ESL) and 36 different languages spoken. Three per cent of the children in the study were members of the Traveller Community. The majority of children $(76 \%)$ were known by the teacher to have attended preschool in the year before commencing fulltime education.

In total, $6.6 \%$ of children had already been identified as having special needs. The study was conducted in mainstream primary schools, and this number does not 
therefore include those children in Cork attending Junior Infants equivalent in special schools, who would tend to be more severely disabled (figure 1).

Parental questionnaires were returned and linked to $865(63 \%)$ valid child questionnaires. The characteristics of the study population varied somewhat between the overall study and those who returned the parental questionnaire. In particular, the proportion of children for whom English was a second language fell from $12.7 \%$ in the overall group to $9.8 \%$ in those returning parental questionnaires; for children reported as having special needs, the proportions were 6.6 and $5.0 \%$, respectively, and for those reported to be members of the Traveller community, $3.1 \%$ and $1.7 \%$, respectively. The characteristics of the population who returned the parental questionnaire and those who did not are compared in table 2.

\section{Distribution of domain scores (mean and SE)}

Mean scores varied across the EDI domains. However, particular groups of children consistently scored below the mean in all domains, that is, boys, children who had English as a second language, members of the Traveller Community, children who had not been to preschool and those who were under the age of 4 years 10 months at the time of the study. This is outlined in figure 2 with the vertical axis representing the mean domain score for the study population.

\section{Factors associated with vulnerability}

Over one-quarter $(28.6 \%)$ of children in the study were developmentally vulnerable (ie, in the lowest 10 th percentile for one or more domains). In total, $12 \%$ were vulnerable in only one domain, $6 \%$ in two domains, $5 \%$ in three domains, $3 \%$ in four domains and $3 \%$ were vulnerable in all the five domains.

The following analysis is based only on the subset of the study population $(n=865)$ on whom the parental questionnaires were returned.

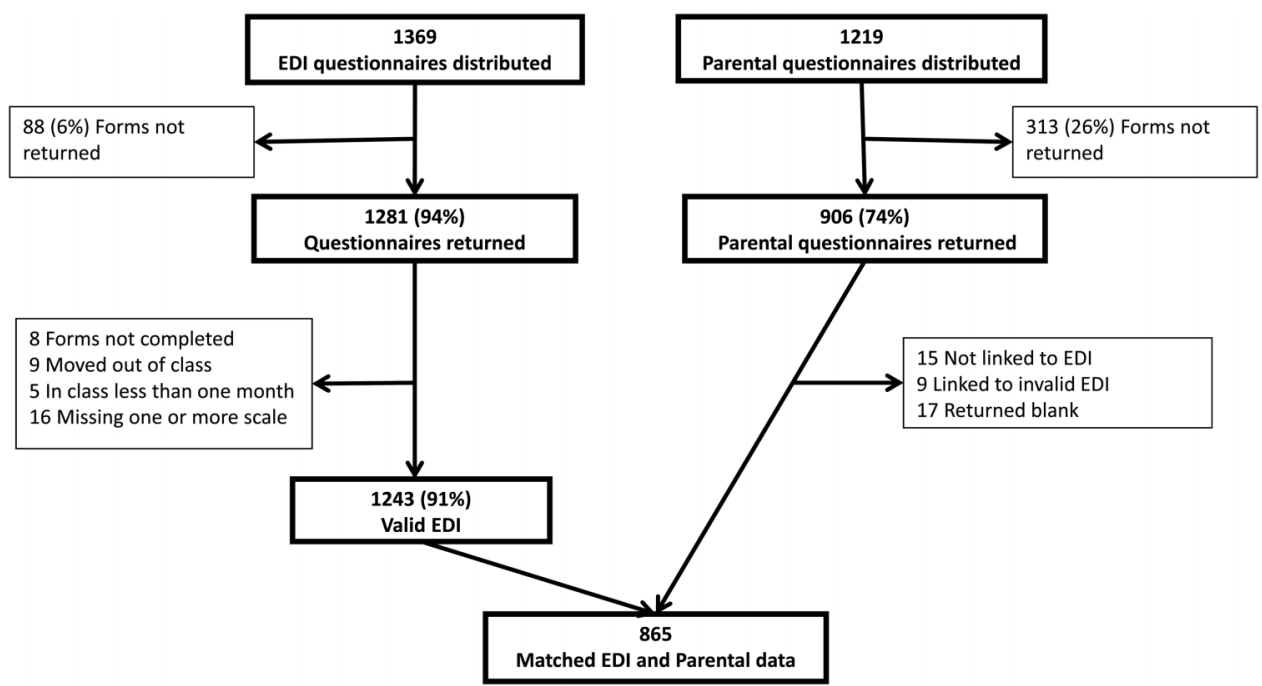

Factors associated with developmental vulnerability (outlined in table 3) were being male (OR 2.2, 95\% CI 1.6 to 3.1), ESL (OR 3.8, CI 2.4 to 6.1), being under 5 years of age at the time of the study (OR 1.6, CI 1.1 to 2.4) and low birth weight (OR 2.5, CI 1.4 to 4.5). When compared with children whose mothers had a university education, those with only primary education (OR 2.8, CI 1.3 to 5.8 ) or secondary level (OR 1.7, CI 1.1 to 2.6) showed higher levels of vulnerability. Children who were never or seldom told stories in the past week and those who spent more than $4 \mathrm{~h}$ watching television or playing video games also showed significantly increased vulnerability.

\section{Logistic regression}

Regression analysis was then used to assess the impact of each variable on the odds of being vulnerable as outlined in table 4 . The first model controlled for being male, having English as a second language and being under 5 years of age at the time of EDI completion; the second controlled for all other factors. Children whose birth weight was less than $2.5 \mathrm{~kg}$ were over twice as likely to be vulnerable. Mother's education showed a graded effect. When controlled for all other variables, children who had not been told or read stories in the previous week were over five times as likely to be vulnerable than those who were told stories every day. In the final model, the amount of time spent watching television became insignificant.

\section{Population attributable fraction}

$\mathrm{PAF}$ was used to measure the proportion of vulnerability attributed to each of the factors included in the final regression model (table 5). Boys were almost three times as likely as girls to be vulnerable and being male accounted for $35 \%$ of the overall vulnerability. English as a second language accounted for $12 \%$, and mother's education (primary, secondary or diploma) for $27 \%$ of vulnerability. Despite the high risk of vulnerability

Figure 1 Participant flow chart. 
Table 2 Comparison between sample for whom parental data were and were not available

\begin{tabular}{|c|c|c|c|}
\hline & $\begin{array}{l}\text { Parental } \\
\mathrm{n}=865\end{array}$ & $\begin{array}{l}\text { No parental } \\
\mathrm{n}=378\end{array}$ & Significance \\
\hline Mean Age-years (SD) & $5.38(0.39)$ & $5.36(0.43)$ & 0.405 \\
\hline English as a second language & $10 \%$ & $19 \%$ & $<0.001$ \\
\hline Identified special needs & $5 \%$ & $10 \%$ & $<0.001$ \\
\hline Member of the Traveller Community & $2 \%$ & $6 \%$ & $<0.001$ \\
\hline Social competence & $8.3(1.8)$ & $7.5(2.1)$ & $<0.001$ \\
\hline Emotional maturity & $7.7(1.6)$ & $7.2(1.7)$ & $<0.001$ \\
\hline Language and cognitive development & $8.8(1.6)$ & $8.0(2.4)$ & $<0.001$ \\
\hline Communication skills and general knowledge & $7.5(2.8)$ & $6.2(3.2)$ & $<0.001$ \\
\hline Percentage of vulnerable in one or more domains of EDI & 23 & 41 & $<0.001$ \\
\hline
\end{tabular}

among children who were not read to (OR 5.3), this only accounted for $1.7 \%$ of the overall vulnerability, reflecting its low prevalence in this population.

\section{DISCUSSION}

This paper explored the extent to which children in a major urban centre in Ireland have attained the level of child development necessary to engage fully in the education process. The findings suggest that, as expected, a significant minority of over one-quarter $(28.6 \%)$ of children in the study were not developmentally ready to engage in and thereby benefit fully from school. Clearly, these findings should be interpreted cautiously in light of the current level of development of EDI in Ireland, in particular, the lack of data on predictive validity for EDI in the Irish population. At the same time, the fundamental issue is not the absolute scores but the unacceptable variation in scores related to the socioeconomic, environmental and ecological circumstances.

The overall level of developmental vulnerability was consistent with the findings from urban areas in Canada where EDI has been implemented. ${ }^{133-35}$ Indeed, the mean scores across all domains in the Irish sample were similar to those in the Canadian normative sample. Factors associated with increased risk of vulnerability at the child level were being male, a younger child, having
English as a second language and low birth weight. Key factors at the family level were mother's education and reading stories. In the final model, the strongest predictor of vulnerability on EDI scores was storytelling. Children who were never told stories in the previous week were over five times as likely to be vulnerable compared with children who were told stories every day. This supports numerous studies which show a link between reading stories and literacy development ${ }^{36}$ and with broader aspects of development ${ }^{37}$ These are again consistent with the findings from Canada, further supporting the transferability of the instrument between the two jurisdictions. $^{38}$

The mean scores across all five domains varied between subgroups of the population. The impact of age is very clear. Younger children aged less than 4 years and 10 months scored, on average, less well across all the domains. Children who had not attended preschool also showed below average scores. However, nonattendance at preschool can result from a variety of underlying reasons. Therefore, these scores cannot be attributed solely to the lack of preschool education. Children from the Traveller Community also showed lower mean scores across all domains. Traveller children face a variety of challenges including accommodation in poorly serviced communal sites, greater risk of low birth weight, ill-health and hospitalisation. ${ }^{39}$
Figure 2 Distribution of scores across all five domains of development. *Each vertical axis represents the population mean for that domain.

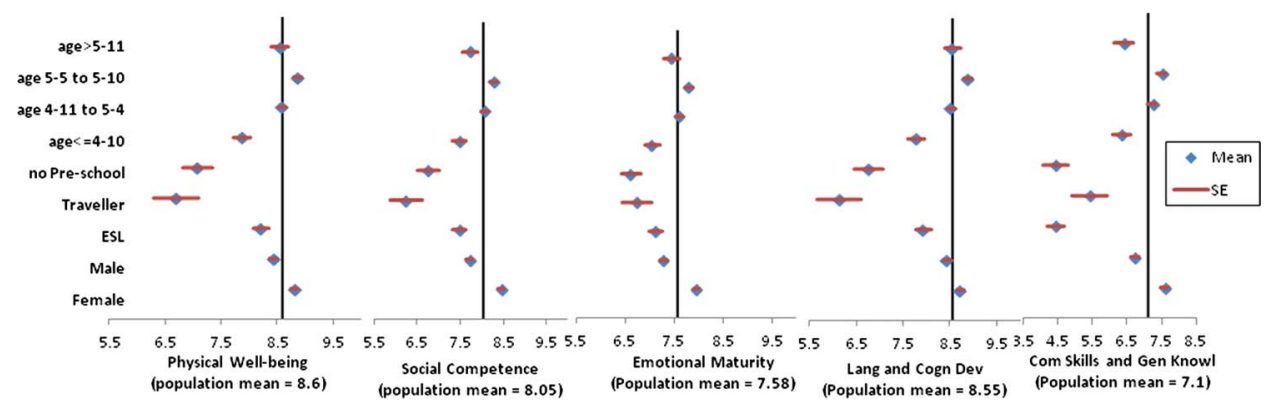


Table 3 Factors associated with developmental vulnerability (univariate analysis)

\begin{tabular}{|c|c|c|c|c|}
\hline & n (\%) & Percentage of vulnerable* & OR & Cl \\
\hline Male & $463(54)$ & 30 & 2.2 & $(1.6$ to 3.1$)$ \\
\hline English as a second language (ESL) & $85(10)$ & 49 & 3.8 & (2.4 to 6.1$)$ \\
\hline Age $<5$ years & $146(17)$ & 31 & 1.6 & (1.1 to 2.4$)$ \\
\hline Low birth weight $(<2500 \mathrm{~g})$ & $49(6)$ & 41 & 2.5 & (1.4 to 4.5$)$ \\
\hline Mother primary education only (ref: University ed) & $38(4)$ & 37 & 2.8 & (1.3 to 5.8$)$ \\
\hline Mother secondary education only (ref: University ed) & $297(34)$ & 27 & 1.7 & (1.1 to 2.6$)$ \\
\hline Four or more hours screen-time per day (ref: $1 \mathrm{~h}$ or less) & $128(15)$ & 32 & 2.0 & (1.2 to 3.4$)$ \\
\hline Never told stories in the past week (ref: every day) & $10(1)$ & 50 & 4.2 & (1.2 to 14.8$)$ \\
\hline Told stories once or twice in past week (ref: every day) & $82(9)$ & 32 & 1.9 & (1.2 to 3.3$)$ \\
\hline No preschool & $44(5)$ & 43 & 2.7 & (1.4 to 5.0$)$ \\
\hline
\end{tabular}

Three child-level demographics were strongly associated with vulnerability. Boys, children who start school at a younger age and those for whom English is a second language were more likely to be vulnerable. PAF illustrates that these three factors account for half of all vulnerability. These findings are consistent with international studies. ${ }^{34} 40$

Hertzman describes vulnerability levels of above $15 \%$ as an unacceptable level of difficulty at school entry age. $^{41}$ There is considerable debate regarding the expected level of biologically determined developmental vulnerability. OECD country estimates range between $1.8 \%$ and $10.4 \%{ }^{42}$ Considering these expected levels of biologically determined developmental delay, external factors can be seen to contribute to major disparities.

\section{Limitations}

The overall study was representative of children in their first year in formal education in Cork city. However, there was a $63 \%$ return rate on the parental questionnaire. While this compares favourably with other jurisdictions where this method has been used, ${ }^{38}$ there are significant differences between those for whom parental data were available and those for whom it was not. It is clear that the most vulnerable children were underrepresented in the parental sample.

This was the first study to use EDI in Ireland. Therefore, there was limited scope for validity testing. Comparisons with Canadian normative data, internal validity testing and qualitative work with teachers indicate that EDI functions well in the Irish context. Future research will consider Rasch modelling and examine issues of predictive validity.

\section{Policy implications}

Epidemiological studies have clearly linked early socioeconomic circumstances to later outcomes. ${ }^{39-41}$ Yet, the specific factors and processes in the early years which contribute to these outcomes have not been adequately explored. The reliance on diagnostic instruments which

Table 4 Logistic regression predicting likelihood of vulnerability on EDI Scores

\begin{tabular}{|c|c|c|}
\hline & OR $(95 \% \mathrm{Cl})^{*}$ & OR (95\% Cl)† \\
\hline Male & 2.5 (1.8 to 3.6$)$ & 2.7 (1.8 to 3.9$)$ \\
\hline ESL & 4.3 (2.6 to 6.9$)$ & 4.5 (2.6 to 7.8$)$ \\
\hline Age $<5$ years & 1.4 (0.9 to 2.2$)$ & $1.3(0.8$ to 2.0$)$ \\
\hline Low Birth Weight & 2.6 (1.4 to 4.9$)$ & $2.6(1.3$ to 5.0$)$ \\
\hline \multicolumn{3}{|c|}{ Mother's education (ref: University education) } \\
\hline Primary or less & 3.1 (1.4 to 6.7$)$ & 2.5 (1.0 to 6.0$)$ \\
\hline Secondary & 2.1 (1.3 to 3.3$)$ & $2.1(1.3$ to 3.4$)$ \\
\hline Diploma & 1.5 (0.9 to 2.3$)$ & 1.5 (0.9 to 2.4$)$ \\
\hline \multicolumn{3}{|c|}{ Daily screen time (ref: $1 \mathrm{~h}$ or less) } \\
\hline $2-3 \mathrm{~h}$ & $1.2(0.8$ to 1.8$)$ & $1.0(0.6$ to 1.6$)$ \\
\hline 4 or more hours & 1.7 (1.0 to 3.0$)$ & $1.2(0.6$ to 2.1$)$ \\
\hline \multicolumn{3}{|c|}{ Stories in the past week (ref: every day) } \\
\hline Never & $3.9(1.0$ to 14.3$)$ & $5.3(1.3$ to 21.1$)$ \\
\hline Once or twice & $1.7(1.0$ to 2.9$)$ & 1.4 (0.8 to 2.5$)$ \\
\hline Many times & $1.2(0.8$ to 1.7$)$ & $1.1(0.7$ to 1.6$)$ \\
\hline No Preschool & 1.9 (1.0 to 3.8$)$ & $1.5(0.7$ to 3.1$)$ \\
\hline
\end{tabular}


Table 5 Population attributable fraction for vulnerability based on OR adjusted for all other variables

\begin{tabular}{lccc} 
& $\mathbf{N}(\%)$ & OR (95\% CI)* & PAF (95\% CI) \\
\hline Under five & $146(17)$ & $1.3(0.8$ to 2.0$)$ & $3.0(-2.8$ to 8.5$)$ \\
Male & $463(54)$ & $2.7(1.8$ to 3.9$)$ & $34.6(21.3$ to 45.7$)$ \\
ESL & $85(10)$ & $4.5(2.6$ to 7.8$)$ & $12.2(7.3$ to 16.8$)$ \\
Low birth weight & $49(6)$ & $2.6(1.3$ to 5.0$)$ & $4.5(1.0$ to 8.0$)$ \\
Mother's education: primary or less & $38(4)$ & $2.5(1.0$ to 6.0$)$ & $2.8(-0.2$ to 5.7$)$ \\
Secondary & $297(34)$ & $2.1(1.3$ to 3.4$)$ & $16.8(5.9$ to 26.5$)$ \\
Diploma & $263(30)$ & $1.5(0.9$ to 2.4$)$ & $7.7(-1.8$ to 16.3$)$ \\
Daily screen time: $2-3$ h & $532(61)$ & $1.0(0.6$ to 1.6$)$ & $-0.3(-21.7$ to 17.3$)$ \\
4 or more hours & $128(15)$ & $1.2(0.6$ to 2.1$)$ & $1.6(-5.2$ to 7.9$)$ \\
Stories in the past week: Never & $10(1)$ & $5.3(1.3$ to 21.1$)$ & $1.7(0.1$ to 3.3$)$ \\
Once or twice & $82(9)$ & $1.4(0.8$ to 2.5$)$ & $2.6(-2.1$ to 7.0$)$ \\
Many times & $251(29)$ & $1.1(0.7$ to 1.6$)$ & $1.7(-6.8$ to 9.5$)$ \\
No preschool & $44(5)$ & $1.5(0.7$ to 3.1$)$ & $1.8(-1.6$ to 5.1$)$ \\
\hline${ }^{*}$ Adjusted for all other variables. & & &
\end{tabular}

are professionally administered and measure particular aspects of development has led to gaps in population level studies on early development outcomes. ${ }^{21}$ EDI is a unique, well-validated population level instrument which allows us to track all five domains of early childhood development. It has the potential to enhance our understanding of the early years environment and identify populations of children at risk of developmental delay. This can, in turn, inform universal programmes to enhance outcomes for whole populations of children. National policy which focuses on the early years is essential with investment in perinatal care, quality support to families and provision of preschool care by highly skilled practitioners. ${ }^{2}$ In Ireland, significant investment is being made in developing a high standard of accessible childcare including a free preschool year and a focus on quality curriculum development. This study was implemented in the year prior to the introduction throughout Ireland of the universally accessible free preschool year and related investment in skills enhancement for preschool staff.

From an Irish perspective, the study raises important questions regarding support to families where English is a second language. ESL was associated with lower mean scores across all domains. The pace of immigration to Ireland increased rapidly between 1990 and 2008, in response to employment opportunities which have since diminished. There is evidence of communities of immigrant populations living in areas of newly emerging disadvantage which lack the support structures associated with established communities. Indeed, this study has identified such communities in which there were vulnerability rates of close to $50 \%$. Particular attention also needs to be focused on the implications of the findings in relation to age. Attendance at school is not mandatory until children are 6 years of age, but they may start once they are four, leading to classes with mixed age groups. Moreover, attendance by children under six in not officially monitored.
Poverty and inequality affect up to one-quarter of Irish children. Throughout the boom years, Irish policy in tackling child poverty consisted almost uniquely of direct payments to families, a practice which is now under threat. Moreover, little consideration was given to creating structures and policies to support and protect families. Tackling child poverty through a strategy of area-based prevention and early intervention features highly on the agenda of the current government. ${ }^{43}$ This focus on both universal and targeted interventions has the potential to contribute to breaking this cycle of poverty. However, effective targeting in the context of early childhood development is problematic, with many instruments providing poor predictive reliability. ${ }^{44}$ There is a need for longitudinal and population-level data that can be linked to administrative sources to provide a holistic basis for effective programming. ${ }^{45}$ In Australia and Canada, EDI is providing just such data on early childhood development.

Early childhood development is a key public health issue that needs to be addressed through a comprehensive programme of targeted and universal approaches, supported by high-quality research. EDI can play a critical role in informing policy and practice at the local and national levels, and allowing for internationally comparable studies on early childhood development.

Contributors MC is the primary author. She conducted the research, worked on the data analysis and produced the manuscript. JM worked on the data analysis and production of data tables. AS advised on the research design and methods of analysis. He also contributed to the manuscript. IP was the instigator of the research. He oversaw the process, contributed to the design, methodology and production of the manuscript and data tables. All authors have read and approved the final manuscript.

Funding This work was supported by the Health Research Board in Ireland under grant number PHD/2007/16

Competing interests None.

Ethics approval For this study was obtained from the Clinical Research Ethics Committee of the Cork Teaching Hospitals, Cork, Ireland.

Data sharing statement No additional data are available.

Provenance and peer review Not commissioned; externally peer reviewed. 


\section{REFERENCES}

1. Kershaw $P$, Forer B. Selection of area-level variables from administrative data: an intersectional approach to the study of place and child development. Health Place 2010;16:500-11.

2. Marmot MG, Allen J, Goldblatt P, et al. on behalf of the Marmot Review, (2010). Fair society, healthy lives: Strategic review of health inequalities in England post-2010. The Marmot Review: London, UK.

3. Power C, Elliott J. Cohort profile: 1958 British birth cohort (National Child Development Study). Int J Epidemiol 2006;35:34-41.

4. Lemelin J-P, Boivin M, Forget-Dubois N, et al. The geneticenvironmental etiology of cognitive school readiness and later academic achievement in early childhood. Child Dev 2007;78:1855-69.

5. Nicholson JM, Lucas N, Berthelsen D, et al. Socioeconomic inequality profiles in physical and developmental health from 0-7 years: Australian National Study. J Epidemiol Community Health 2012;66:81-7.

6. Leventhal T, Brooks-Gunn J. The neighborhoods they live in: the effects of neighborhood residence on child and adolescent outcomes. Pshychol Rev 2000;126:309-37.

7. Heckman JJ, Masterov DV. The productivity argument for investing in young children. Appl Econ Perspect Policy 2007;29:446-93.

8. Kershaw $\mathrm{P}$, Warburton $\mathrm{B}$, Anderson $\mathrm{L}$, et al. The economic costs of early vulnerability in Canada. Can J Public Health 2010;101(Suppl 3):S8-12.

9. Maggi S, Roberts W, MacLennan D, et al. Community resilience, quality childcare, and preschoolers' mental health: A three-city comparison. Social Science \& Medicine 2011;73:1080-87.

10. Furumoto-Dawson A, Gehlert S, Sohmer D, et al. Early-life conditions and mechanisms of population health vulnerabilities. Health Aff (Millwood) 2007;26:1238-48.

11. Guhn M, Janus M, Hertzman C. The early development instrument: translating school readiness assessment into community actions and policy planning. Early Educ Dev 2007;18:369-74.

12. Rose G. Sick individuals and sick populations. Int $J$ Epidemiol 1985;14:32-8.

13. Guhn M, Gadermann A, Zumbo BD. Does the EDI measure school readiness in the same way across different groups of children? Early Educ Dev 2007;18:453-72.

14. Avan $\mathrm{BI}$, Kirkwood B. Review of the theoretical frameworks for the study of child development within public health and epidemiology. $J$ Epidemiol Community Health 2010;64:388-93.

15. Janus M, Brinkman S, Duku E. Validity and psychometric properties of the early development instrument in Canada, Australia, United States, and Jamaica. Soc Indicators Res 2011;103:283-97.

16. Brinkman SA, Gialamas A, Rahman A, et al. Jurisdictional, socioeconomic and gender inequalities in child health and development: analysis of a national census of 5-year-olds in Australia. BMJ Open 2012;2:e001075. doi:10.1136/bmjopen-2012-001075

17. C.S.O. Profile 7: religion, ethnicity and irish travellers. Cork: Central Statistics Office, 2012

18. Haase T, Pratschke J. Deprivation and its spatial articulation in the republic of Ireland. Dublin: Area Development Management, 2005.

19. OMCYA. State of the nations children. Dublin: Office of the Minister for Children and Youth Affairs, 2010.

20. Janus M, Brinkman S, Duku E, et al. The early development instrument: a population-based measure for communities. Hamilton, Ontario: Offord Centre for Child Studies, McMaster University, 2007.

21. Janus M, Offord DR. Development and psychometric properties of the early development instrument (EDI): a measure of children's school readiness. Can J Behav Sci Rev Can Sci Comportement 2007;39:1-22.
22. D'Angiulli A, Warburton W, Dahinten S, et al. Population-level associations between preschool vulnerability and grade-four basic skills. PLoS ONE 2009;4:e7692.

23. Brinkman S, Silburn S, Lawrence D, et al. Investigating the validity of the Australian early development index. Early Educ Dev 2007;18:427-51.

24. Muhajarine N, Puchala C, Janus M. Does the EDI equivalently measure facets of school readiness for aboriginal and non-aboriginal children? Soc Indicators Res 2011;103:299-314.

25. Williams J, Greene S, Doyle E, et al. Growing up in Ireland national longitudinal study of children. The lives of 9 year olds. The Stationery Office, 2009.

26. Morgan K, McGee H, Watson D, et al. SLAN 2007: survey of lifestyle, attitudes \& nutrition in Ireland: main report. Dublin: Department of Health and Children, 2008.

27. Brinkman S, Sayers M, Goldfeld S, et al. Population monitoring of language and cognitive development in Australia: the Australian early development index. Int J Speech Lang Pathol 2009;11:419-30.

28. Carey DJ. The essential guide to special education in Ireland. Dublin: Primary ABC, 2005.

29. O'Sullivan JJ, Pearce MS, Parker L. Parental recall of birth weight: how accurate is it? Arch Dis Child 2000;82:202-3.

30. Hanley JA. A heuristic approach to the formulas for population attributable fraction. J Epidemiol Community Health 2001;55:508-14

31. Miettinen OS. Proportion of disease caused or prevented by a given exposure, trait or intervention. Am J Epidemiol 1974;99:325-32.

32. Greenland S, Drescher K. Maximum likelihood estimation of the attributable fraction from logistic models. Biometrics 1993;49:865-72.

33. Carpiano RM, Lloyd JEV, Hertzman C. Concentrated affluence, concentrated disadvantage, and children's readiness for school: a population-based, multi-level investigation. Soc Sci Med 2009;69:420-32.

34. Janus M, Duku E. The school entry gap: socioeconomic, family, and health factors associated with children's school readiness to learn. Early Educ Dev 2007;18:375-403.

35. Kohen D, Oliver L, Pierre F. Examining the effects of schools and neighbourhoods on the outcomes of Kindergarten children in Canada. Int J Speech Lang Pathol 2009;11:404-18.

36. Bus AG, Van ljzendoorn $\mathrm{MH}$. Mothers reading to their 3-year-olds: the role of mother-child attachment security in becoming literate. Reading Res Q 1995;30:998-1015.

37. Fletcher KL, Reese E. Picture book reading with young children: a conceptual framework. Dev Rev 2005;25:64-103.

38. Janus M. Transition to school. In: Laverick DM, Jalongo MR, eds Transitions to early care and education. The Netherlands: Springer, 2011:177-87.

39. Abdalla S, Cronin F, Daly L, et al. Our Geels: all Ireland Traveller Health Study. Dublin: University College Dublin, 2010.

40. Maggi S, Irwin LJ, Siddiqi A, et al. The social determinants of early child development: an overview. J Paediatr Child Health 2010;46:627-35.

41. Hertzman C. The state of child development in Canada: are we moving toward, or away from, equity from the start? Paediatr Child Health 2009;14:673-6.

42. Banks J, McCoy S. A study on the prevalence of special educational needs. Dublin: Economic and Social Research Institute, 2011.

43. Expenditure DoP, ed. Programme for Government 2011-2016. Dublin, 2011.

44. Lynch JW, Law C, Brinkman S, et al. Inequalities in child healthy development: some challenges for effective implementation. Soc Sci Med 2010;71:1244-8.

45. Hertzman C, Williams R. Making early childhood count. Can Med Assoc J 2009;180:68-71. 